\title{
PRIMEIROS DISCURSOS DE RECEPÇÃO DA FILOSOFIA DE NIETZSCHE NO BRASIL PUBLICADOS NOS DIÁRIOS E PERIÓDICOS NACIONAIS (1900-1935)
}

Geraldo Dias $^{1}$

\section{Resumo:}

Visamos a apresentar aqui os primeiros discursos de recepção da filosofia de Nietzsche no Brasil, originalmente publicados em periódicos, jornais, revistas e almanaques do início do século XX. Para tanto, num primeiro momento, iremos discorrer sobre o estado da pesquisa de recepção da sua filosofia no Brasil e o nosso projeto de estudo do tema. Em seguida, de forma geral, sinalizaremos a forma como ela foi recepcionada na impressa brasileira do período. Por fim, daremos a conhecer como e por quem a filosofia nietzschiana foi primeiramente lida e discutida em nosso país.

Palavras-chaves: Nietzsche, recepção, Brasil, periódicos.

\section{Status quaestionis}

Na filosofia nietzschiana, o leitor tem importância fundamental, tanto é verdade que ao longo de sua obra o próprio Nietzsche deixou inúmeras orientações, diretrizes e sugestões de como pretendia ser $\operatorname{lido}^{2}$. Em conformidade a isso, seria inclusive relevante

\footnotetext{
${ }^{1}$ Mestre em Filosofia pela Universidade Federal de São Paulo (UNIFESP), São Paulo, Brasil. Membro do GEN - Grupo de Estudos Nietzsche. E-mail: ge.pdias@ hotmail.com. Esse texto é parte de meu projeto de doutorado que, sob a orientação do Prof. Dr. Ivo da Silva Júnior, será apresentado ao departamento de Filosofia da Escola de Filosofia, Letras e Ciências Humanas (EFLCH) ainda neste ano de 2014.

${ }^{2}$ Nietzsche sempre procurou selecionar seus leitores: "O leitor do qual espero alguma coisa tem de ter três propriedades: deve ser calmo e ler sem pressa, não deve sempre privilegiar a si mesmo e intrometer a sua 'formação' (Bildung), não lhe é permitido, por fim, esperar na conclusão algo como um resultado, uma listagem" (BA/EE, Prólogo I, KSA 1. 648). Ele não os poupava e inclusive se preveniu contra distorções e apropriações indevidas: "Quem acreditou ter entendido algo de mim, havia ajustado algo de mim à sua imagem - não raro um oposto de mim, por exemplo, um "idealista"; quem não entendeu nada de mim, negava que eu em geral entrasse em consideração”. (EH, Por que escrevo livros tão bons, §1).
} 
deslocar a perspectiva de estudo de sua filosofia para os leitores de suas obras. Abordálas não mais a partir da premissa de que nelas há teses e estruturas lógicas que levariam todos os seus leitores sempre às mesmas teses e argumentos. Tampouco querer desvendá-las a partir do vínculo entre vida e obra. Agora é chegado o momento de estudar a filosofia de Nietzsche a partir de seus leitores, a partir do grau de incorporação que dela eles são capazes de realizar, privilegiando assim o estudo de sua recepção. Isso porque, afinal, sua filosofia não é um objeto que existe em si, oferecendo a todos os leitores, de diferentes contextos e épocas, as mesmas teses e argumentos, uma mesma ordem factual de vivências. E, no âmbito da pesquisa nacional, já é tempo de investigarmos a dimensão histórica da recepção de sua filosofia no Brasil, isto é, examinarmos as impressões de seu pensamento na literatura filosófica brasileira, investigarmos quem têm sido seus leitores e ouvintes, refletirmos sobre as consequências e os resultados de sua filosofia para a história das ideias nacionais.

Desde o final do século XIX estão em curso no Brasil diversas incorporações da filosofia de Nietzsche, sejam por meio de leituras utilitárias, abordagens superficiais, referências indiretas, entre interpretações as mais contrastantes, o fato é que ela passou a ganhar corpo e integrar-se aos registros literário e filosófico, tornando-se cada vez mais presente em diversos grupos e círculos intelectuais. Atualmente, contudo, não há um estudo sistemático sobre a recepção da filosofia de Nietzsche nos domínios de nossa cultura. Não obstante, dada às proporções que ela tomou, seria relevante investigarmos seus impactos no projeto modernista de renovação cultural e rompimento com a tradição literária anterior; e também examinarmos como a iniciante filosofia acadêmica do mesmo período acolheu seu pensamento ${ }^{3}$.

\footnotetext{
Indignou-se com a recepção de sua filosofia, com o "não-entendimento" de seus escritos, nesse sentido, veja-se o trabalho "Desfigurações e desvios. Acerca da recepção de Nietzsche na Alemanha", de MARTON, S. Nietzsche na Alemanha (org). São Paulo: Discurso Editarial, 205 (Coleção Sendas e Veredas. Série recepção), 2005, p. 13-49. Acerca do problema "como ler Nietzsche hoje?", houve quem defendesse "a tese de que não são as leituras que constituem" o texto de sua filosofia; que ela sempre "permanece o que é, independemente delas", iden, p.31. Contra essa tese, sabemos hoje que no caso de Nietzsche houve até mesmo a imposição de um texto filosófico sugerido como sendo sua obra capital, $A$ vontade de potência, uma farsa produzida por sua irmã, texto este que serviu aos ideólogos nazifascistas.

3 A filosofia nietzschiana era então objeto de estudos, palestras e conferências realizadas nos estabelecimentos de ensino da época, como na Escola Normal Primaria de casa Branca ou na Faculdade de philosophia e Letras. Nesta última, o escritor francês G. Dumas, conforme notícia o jornal Correio Paulistano de1913, realizou a conferência "A philosophia de Nietzsche". Aqui, porém, iremos trabalhar apenas o registro literário, mais especificamente os primeiros discursos de recepção da filosofia de Nietzsche no Brasil pré-modernista.
} 
Assim, inspirados na estética da recepção de Hans Robert Jauss ${ }^{4}$, estudaremos as impressões deixadas pelas ideias de Nietzsche na literatura e na cena acadêmicofilosófica brasileira do início do século XX. Nestes dois registros investigaremos as impressões deixadas pela sua filosofia na cultura literária e na história das ideias de nosso país, preenchendo assim uma lacuna na pesquisa nietzschiana nacional. Trata-se de mensurar o quanto a sua filosofia impactou a intelectualidade nacional rumo à antecipação de "possibilidades não concretizadas", à expansão de espaços limitados, na direção de novos caminhos para a experiência intelectual ${ }^{5}$. Conjecturamos que a recepção da filosofia de Nietzsche no Brasil se realizou na medida em que foi, por um lado, incorporada à proposta modernista de uma renovação cultural frente à tradição literária anterior (parnasiana, por exemplo, e demais correntes consideradas arcaicas) e, por outro, integrada à cena acadêmico-filosófica, que então buscava uma forma de pensar liberta dos pressupostos do ecletismo, do espiritualismo e do positivismo.

Dada à carência no estudo de recepção entre nós, pois "são ainda raros os trabalhos sobre a recepção das ideias filosóficas no Brasil", é preciso superar a escassez de trabalhos sobre a recepção da filosofia de Nietzsche ${ }^{6}$. Isso porque, apenas eventualmente encontram-se trabalhos que contribuem para tal pesquisa, como é o caso do texto "Nietzsche e a cena brasileira", de Scarlett Marton, um pequeno apêndice. Trata-se de "um primeiro e grande passo nessa direção", isto é, na pesquisa de recepção da filosofia de Nietzsche no Brasil. No entanto, de modo geral constata-se uma grande lacuna quanto a esse tema, em outras palavras, "[a] recepção da filosofia de Nietzsche no Brasil é ainda um capítulo que precisa ser devidamente estudado" 7.

\section{A recepção da filosofia nietzschiana na impressa brasileira}

A imprensa brasileira do início do século $\mathrm{XX}$ recepcionou a filosofia de Nietzsche de forma ampla, indireta e difusa. Ela reverbera o clima cultural no qual se desenvolveu os primeiros discursos de recepção das ideias de Nietzsche no Brasil, a maneira como seu pensamento, suas obras e a sua filosofia foram inicialmente integradas por meio de diários e periódicos da época.

\footnotetext{
${ }^{4}$ Isto é, a partir de seus “(...) critérios de recepção, do efeito produzido pela obra e de sua fama junto à posteridade (...)". JAUSS, Hans Robert. A história da literatura como provocação à teoria literária. Trad. Sérgio Tellaroli, Ed. Ática, São Paulo, 1994, p. 7-8.

${ }^{5}$ Iden, p.52.

${ }^{6}$ MARTON, S. Extravagâncias. Ensaios sobre a filosofia de Nietzsche. $3^{\circ}$ ed. São Paulo: Discurso Editorial e Editora Barcarolla, 2009, p.253.

${ }^{7}$ SILVA JR, I. Notas sobre a recepção de Nietzsche no Brasil. Lebrun e os operadores teóricos, in Cadernos Nietzsche n ${ }^{\circ}$ 30, São Paulo, 2012, p.121.
} 
As ideias de Nietzsche então se faziam presentes em artigos, ensaios, crônicas, resenhas, em frases soltas - às vezes aparentemente sem pretensões ou direcionadas para propagandas, ora política, ora comercial -, em transcrições de textos traduzidos em português ou francês. A partir do final do século XIX e início do XX, diários, revistas e almanaques começam a recepcionar a filosofia de Nietzsche de maneira ampla e difusa, no sentido que de não havia propriamente discursos de recepção, mas ecos difusos. Abordado por intelectuais diversos, Nietzsche aparece ligado à crítica teatral, em resenhas de obras literárias a ele dedicadas e/ou nele inspiradas, em discussões sobre guerra, música, o feminismo, 'o altruísmos niilista', 'o neo-espiritismo cristão', enfim, nos assuntos mais variados. $\mathrm{O}$ que poderíamos chamar de intelectuais profissionais da comunicação (às vezes anônimos), cronistas, ensaístas, romancistas, poetas, acadêmicos, intelectuais diletantes, enfim, todos recepcionavam as ideias de Nietzsche e o considerava um filósofo à moda. Era incorporado diversamente, abordado quase sempre de maneira grandiloquente, sob a ótica de hipérboles, em títulos como "Nietzsche, o grande lutador" ${ }^{8}$ ou "Nietzsche, o grande solitário" 9 , apreciado como grande gênio do século, mas também como louco e perturbado, ora como filósofo metafísico, pragmático, vitalista, existencialista, também como músico, "um verdadeiro poeta dos sons", ora herói defensor da civilização e da cultura, ora vilão acusado de inspirar Guerras Mundiais. Tão diversificadas foram - e ainda são - as formas de abordar as obras e as ideias de Nietzsche no Brasil, uma verdadeira pluralidade de interpretações, utilizações e incorporação que não é possível de imediato sabermos de que modo, afinal, sua filosofia foi recepcionada. O fato é que, por meio da imprensa, diversos intelectuais discutiam as suas ideias, de modo que elas passaram a ser recepcionadas e difundidas largamente, porém de maneira difusa e paradoxal.

\footnotetext{
${ }^{8}$ Título do artigo publicado por Ribeiro F no Correio Paulistano por ocasião do aniversário de 90 anos do nascimento de Nietzsche, em 1934 (também publicado no diário O Paiz, em19/10/1934). O Correio Paulistano foi o primeiro jornal de São Paulo que prosperou. Fundado por Joaquim Roberto de Azevedo Marques, nasceu com a aspiração de ser imparcial, mas trocou de posicionamento político diversas vezes em sua trajetória. Foi um dos jornais paulistanos a apoiar a Semana de Arte Moderna, em fevereiro de 1922. O diário tinha o modernista Menotti Del Picchia entre seus colaboradores, justificando o motivo de um jornal conservador ter tomado um posicionamento tão arrojado enquanto a Folha da Noite desqualificava os modernistas e suas criações. De 1930 a 1934, permanece fechado em cumprimento de ordem do presidente Getúlio Vargas, por apoiar a República Velha. De volta à circulação, o jornal é publicado até 31 de julho de 1963, quando é fechado.

${ }_{9}^{9}$ Título do artigo publicado por Sylvia Patricia em 17 de Novembro de 1935 no Correio Paulistano.
} 
O Correio da Manhã ${ }^{10}$ recepcionou Nietzsche como um filósofo paradoxal e controverso, ao mesmo tempo gênio, louco, poeta, erudito, filólogo, escritor, literato, ensaísta, revolucionário, etc. Como se tratava de um filósofo à moda, seu nome aparece em contextos os mais inusitados. Sua filosofia era ainda totalmente desconhecida, mas seu nome e suas ideias estavam na boca de intelectuais/autores e leitores os mais diversos. A filosofia de Nietzsche se prestava a todo tipo de apropriação, sua ideia mais citada, übermensch - oriunda de sua obra mais conhecida e apreciada à época, Assim falou Zaratustra -, geralmente traduzida por sobre-homem ou super-homem, em certo momento torna-se um jargão, conhecida e utilizada por todos, empregada para enaltecer exageradamente personalidades ilustres. George Washington figura, na opinião de Benjamin Lima, um colaborador do diário, como o "authentico super-homem". O barão do Rio Branco, por ocasião de seu falecimento, é saldado com a expressão "um nosso super-homem”, empregada por Candido Jucá em 13 de Fevereiro de 1912, sustentando que “o barão do Rio Branco foi um verdadeiro super-homem”. Segundo o anarquista e crítico literário José Oiticica, a personagem Ladice, do romance Exaltação, de Albertina Bertha, "surpreende a crítica, pois figura como um tipo novo, uma super-mulher, portadora de alma e moral aristocrática” de inspiração nietzschiana.

\section{Quando e por quem a filosofia de Nietzsche foi recepcionada no Brasil?}

Os primeiros intelectuais que recepcionaram a filosofia de Nietzsche no país foram Nestor Victor, numa resenha crítica publicada em 26 de Dezembro de 1900, no diário O Paiz; ${ }^{11}$ Araripe Junior, num breve estudo composto em 1902, publicado primeiramente em 1904 no Almanaque Garnier e reeditado em 1913 na Revista da Semana; ${ }^{12}$ José Veríssimo, que publicou um artigo em 1903 no diário Correio da

\footnotetext{
${ }^{10}$ Fundado por Edmundo e Paulo Bittencourt no Rio de Janeiro, o diário tentava se destacar dando ênfase à informação em detrimento da opinião. Foi perseguido e fechado em diversas ocasiões, tendo os seus proprietários e dirigentes presos, provalvemente por fazer oposição a quase todos os presidentes do país; publicou do período de 1901 até 1974. Por ser opositor do governo, o Correio da Manhã não sobreviveu ao regime militar. Colaboraram para o períodico escritores como Lima Barreto, Carlos Drummond de Andrade, Otto Maria Carpeaux, entre outros.

${ }^{11}$ Jornal de grande circulação, lançado no dia $1^{\circ}$ de outubro de 1884 , no Rio de Janeiro, pelo empresário João José dos Reis Júnior, o conde de São Salvador de Matozinhos. Tido como o mais robusto órgão governista da República Velha, foi um dos principais formadores de opinião da sociedade brasileira, entre o fim do século XIX e o começo do século XX. Durou até 18 de novembro de 1934, quando foi fechado pela Revolução de 1930.

${ }^{12}$ Considerada a primeira revista brasileira e publicada no Rio de Janeiro, a Revista da Semana era um semanário, foi editada de 1900 a 1962. Seu enfoque era principalmente político, tendo muitos intelectuais e artistas da época colaborarado para as suas páginas.
} 
Manhã e, finalmente, por João Ribeiro, que publicou um artigo no ano de 1904 no anuário Almanaque Garnier, reeditado em 1910, no seu livro O Fabordão.

No breve artigo F. Nietzsche, Nestor Victor discorre sobre o filósofo ao escrever uma resenha crítica sobre Pages Choisies, de Henri Albert. De início exprime-se a respeito do "sentimento de probidade intelectual" segundo ele "levado á loucura" por Nietzsche. Seu texto gira em torno do neologismo cabolin/calinage que, por sua vez, indica a ideia de "nihilismo". Como ele afirma, "a cabolinage" é "o decrescimento do enthusiasmo organicamente vital, o caminhar lento, preguiçoso, mas positivo para o nihilismo". Mostra-se mais preocupado em refletir sobre as consequências do "nihilismo" para o "homem moderno" do que propriamente sobre a filosofia nietzschiana. Tenta tirar conclusões pouco claras e/ou difusas a partir dela, ao afirmar que em Nietzsche a "probidade é, em ultima analyse, uma probidade á Brutus". Minimiza-o ao defender que "Nietzsche, por outro lado, tem consciencia da grandeza humana desenvolvida, no seu maximo gráo; mas nenhuma vez se lembra da relatividade d'essa grandeza, do nada que ella representa em face do Universo". De forma ambígua defende que a loucura de Nietzsche é venerável, por ser ele um perseguidor de falsas "pretenções", por isso adverte que para quem possui valor ele pode ser um louco amigo, mas para as falsas inteligências seus "olhos" "serão sempre uma ironia corrosiva, um sarcasmo dissolvente, impiedosos e fataes".

O breve estudo Ulysses e Dionysio, publicado pela primeira vez no Almanaque Garnier $^{13}$ de 1904, depois também reeditado na Revista da Semana do mês de Maio de 1913, revela a presença das ideias estéticas de Nietzsche no Brasil. Araripe Júnior aborda a "obra Origens da tragédia" e afirma que nela "Nietzsche explica a decadência grega e a de todo o Ocidente, pela morte do espírito dyonisiaco". Contudo, de maneira precipitada, julga que "por mais respeitável que seja a concepção do philosopho alemão, é licito fazer algumas interrogações". Sustenta que na “opinião de Nietzsche (...) Ulysses, ou melhor, o gênio jônico é a causa efficiente do declive em que o mundo se perde", e por isso questiona a insuficiência do espírito dionisíaco em fase do predomínio moderno do espírito apolínio. O texto de Araripe é modesto e ele não responde nem conjectura seus questionamentos sobre a concepção estética de Nietzsche.

\footnotetext{
${ }^{13}$ Mais conhecido como Almanaque Garnier, foi um períodico anuário criado em 1903 e mantido até 1914. Empreendimento gráfico Frances (isto é, propriedade de dois irmãos franceses, instalado na capital da república), a primeira edição data de 1903, pela Livraria Ganier do Brasil. Sua linha editorial se dirigia a comerciantes, estudantes, profissionais liberais, políticos e autoridades da então capital do Brasil e também de São Paulo.
} 
Suas interrogações não partem do próprio filósofo, mas do "ponto de vista moderno", realizando assim apenas uma abordagem indireta da filosofia estética nietzschiana.

José Veríssimo, por sua vez, no artigo "Um Nietzsche differente”, logo de início firma que "Nietzsche está na moda". Com isso ele nos apresenta o clima cultural do momento e à maneira como a filosofia nietzschiana era então recepcionada no país: "em função do seu temperamento", no sentido de que "quando uma philosophia ou um philosopho e suas doutrinas estão em moda, é que correspondem á índole do momento, ou, pelo menos, ás aspirações e sentimentos, ao estado d'alma, de grupos sociais". Veríssimo nos remete ao clima de renovação cultural em curso no Brasil de então, impactado tanto pela forte imigração, quanto pela crescente análise que os autores tendem a realizar sobre o país, os chamados intérpretes do Brasil.

$\mathrm{O}$ artigo de Veríssimo nos transporta para esse clima de efervescência cultural pré-modernista, seu discurso aponta para os "intelectuaes" considerados modernos, uma "porção" de intelectuais que "caminhou resolutamente ao encontro do poeta philosopho da Fala de Zarathustra, acclomou-o senhor e mestre, adoptou a sua doutrina contradictoria e vaga (...)". Sugere assim que as aspirações pré-modernistas e a filosofia de Nietzsche possuem afinidades. Esses intelectuais, como ele mesmo diz, "tudo quizera destruir, para crear em lugar um mundo novo, onde a expansão do indivíduo encontrasse as máximas possibilidades, livre, enfim, de todos os 'preconceitos' sociais, espirituaes e moraes, que atrapalham e empecem". Nesse clima cultural de rompimento com a tradição considerada arcaica, sejam na literatura ou nas artes plásticas, a obra, as ideias e, enfim, a filosofia nietzschiana passa a ser uma importante fonte de referência para a 'regeneração' artística nacional.

Datado de 1896 e publicado no anuário Almanaque Garnier de 1904, João Ribeiro ${ }^{14}$ assina de Berlin o texto Frederico Nietzsche, no qual começa tratando da "negra loucura [que] obscureceu o gênio" do filósofo. Não faz "uma exposição da philosophia de Nietzsche", vê nele antes "um grande estranhável inimigo dos systemas", escritor de "ensaios e aforismos". Concede-lhe o estatuto de "philosopho", de "philologo, erudito, litterato e artista genial da palavra, poeta". Aparenta certa dificuldade para traduzir o conceito übermensch, transcrevendo-o ora por "prohomem", às vezes "sobre-homem", ora utilizando "pro-homem"; sobre tal ideia considera que "Nietzsche sonhava a [sua] evolução" por meio de uma "seleção nova" e "não pelo

\footnotetext{
${ }^{14}$ Intelectual conhecido como "profeta do nosso Modernismo", in BOSI, Alfredo. História concisa da literatura brasileira. 43 ed. - São Paulo: Cultrix, 2006, p. 336.
} 
processo darwinico ou goethiano". Contra a "Chistandade", sustenta que Nietzsche "queria" a "a inversão de todos os valores". J. Ribeiro não apresenta suas fontes de consulta e leitura. Sua abordagem é interposta por tantos temas diferentes - o individualismo, o cristianismo, a mulher - que, embora façam parte do universo de pensamento nietzschiano, não logra a apresentar algo conceitual ou filosoficamente consistente sobre a filosofia do pensador alemão. Seria apenas uma verdadeira miscelânea de temas misturados se J. Ribeiro não tivesse centrado seu discurso no tema da moral. Não era intento seu, pois lhe falta "os elementos de perspectiva indispensáveis", "dar um escorço siquer de todo a obra de Nietzsche, que, embora fragmentaria, é todavia muito volumosa". Seu discurso de recepção da filosofia de Nietzsche, como ele mesmo confessa, é entusiástico e, ao mesmo tempo, sufocado pelo “âmbito da vida allemã em que momentaneamente" se encontrava.

\section{Conclusão}

Em todos os discursos aqui apresentados ressalta-se o fato de que Nietzsche, suas obras e ideias, são abordadas de maneira intermediária. Sempre de modo não direto é que se procura absorver algo novo - Nietzsche, suas obras, suas ideias -, nunca por uma decisão própria, direta, em linha reta com o próprio filósofo, mas sempre fazendo muitas voltas. Tratada por desvios, de forma oblíqua e entortada por preconceitos nacionais e estrangeiros -, assim a filosofia de Nietzsche foi recepcionada no Brasil, isto é, amplamente, por variados intelectuais, em diversos diários, periódicos e almanaques, porém, sempre de maneira dissimulada, ambígua, duvidosa e equivocada.

Os primeiros discursos de recepção da filosofia de Nietzsche aqui citados não formam propriamente um discurso, mas ecos difusos, pelo menos no sentido de não apresentarem uma abordagem conceitual e filosófica, lógica e ordenada, mas sempre um discurso conduzido pelo entusiasmo da novidade, da moda. Assim a filosofia de Nietzsche foi recepcionada pela imprensa brasileira que, por meio de seus colaborados, profissionais da comunicação em geral, pela intelectualidade, por amadores e acadêmicos ainda não especializados ele foi lido, ruminado, foi incorporado em pedaços, mediado por traduções ora francesa ou portuguesa e pelas voltas e reviravoltas das recepções estrangeiras.

\section{Referências Bibliográficas}


BOSI, Alfredo. História concisa da literatura brasileira. 43 ed. - São Paulo: Cultrix, 2006.

Hans Robert. A história da literatura como provocação à teoria literária. Trad. Sérgio Tellaroli, Ed. Ática, São Paulo, 1994.

MARTON, S. Extravagâncias. Ensaios sobre a filosofia de Nietzsche. $3^{\circ}$ ed. São Paulo: Discurso Editorial e Editora Barcarolla, 2009.

Nietzsche na Alemanha (org). São Paulo: Discurso Editarial, 205 (Coleção Sendas e Veredas. Série recepção), 2005.

MARQUES, A. Observações sobre a recepção de Nietzsche em Portugal: passando por Pessoa até finais da década de noventa do século $X X$, in Cadernos Nietzsche $n^{\circ} 31$, SP, GEN, 2012.

NIETZSCHE, F. Sämtliche Werke. Kritische Studienausgabe (KSA). Organizada por Giorgio Colli e Mazzino Montinari. Berlim : Walter de Gruyter \& CO., 1988. 15 v.

Obras incompletas. Trad. Rubens Rodrigues Torres Filho. São Paulo: Nova Cultural, 1996 (Col. "Os Pensadores”).

SILVA JR, I. Notas sobre a recepção de Nietzsche no Brasil. Lebrun e os operadores teóricos, in Cadernos Nietzsche ${ }^{\circ}$ 30, São Paulo, 2012. 